УДК 903.532

DOI 10.18413/2687-0967-2020-47-1-107-112

\title{
НАЗНАЧЕНИЕ ДОЛЬМЕНОВ ЗАПАДНОГО КАВКАЗА
}

\section{INTENTION OF THE WESTERN CAUCASUS DOLMENS}

\author{
Н.И. Бондарев, Т.А. Бондарева \\ N.I. Bondarev, T.A. Bondareva \\ Орловский государственный университет, Россия, 302026, г. Орел, ул. Комсомольская, 95 \\ Orel State University, 95 Komsomol'skaya St, Orel, 302026, Russia \\ E-mail: nikbond@inbox.ru
}

\begin{abstract}
Аннотация
В представленной работе проведен критический анализ наиболее интересных гипотез предназначения дольменов Западного Кавказа. Приведен ряд аргументов, свидетельствующих против основной научной гипотезы их назначения, существующей в настоящее время - сооружения для погребений, главным из которых является полное отсутствие в подавляющем большинстве дольменов остатков погребального содержимого. На основе анализа личных исследований и данных литературных источников предложена и обоснована новая и наиболее вероятная гипотеза первоначального назначения дольменов Западного Кавказа - укрытия для детей от крупных хищников, случайных одиночных охотников из других племен и некоторых стихийных явлений.
\end{abstract}

\begin{abstract}
In the present article the critical analysis of the most interesting hypotheses of the appointment of dolmens of the Western Caucasus is carried out. A number of the arguments testifying against the main scientific hypothesis of their appointment existing now - constructions for burials is given. The main argument against this hypothesis is the complete absence of remains of burial contents in the vast majority of dolmens. The authors proposed and substantiated a new and most probable hypothesis of the initial appointment of the dolmens of the Western Caucasus. Dolmens served as shelters for children from large predators, random single hunters from other tribes and some natural phenomena. In favor of the hypothesis put forward by us testify the location, design and size of dolmens, their orientation on the sides of the world, as well as the way of life and living conditions of the population living at that time. The proposed hypothesis does not reject the possibility of later use of part of the dolmens for burial.
\end{abstract}

Ключевые слова: дольмены, дома «карликов», назначение дольменов, сооружения для погребений, укрытия для детей.

Key words: dolmens, houses «dwarfs», appointment of dolmens, burial facilities, shelters for children.

Среди культурного наследия, дошедшего к нам с древних времен, выделяются загадочные строения - дольмены, оставленные древними народами, заселявшими территорию современного Краснодарского края России. Дольмены, как следует из Большой Советской Энциклопедии, древние погребальные сооружения, сложенные из нескольких огромных каменных глыб и плит, поставленных вертикально и покрытых сверху массивной горизонтальной плитой [БСЭ, 1952].

Впервые о дольменах на Кавказе сообщил академик Петр Симон Паллас в 1794 году. Позже изучением дольменов занимались А.С. Уваров, Е.Д. Фелицын, В.А. Городцов. Во второй половине двадцатого века глубокое изучение дольменов проводил В.И. Марковин, опубликовавший о них ряд статей и монографий [Марковин, 1973, 1974, 1978, 1985, 1994, 1997 , 2000, 2004]. Возраст древнейших дольменов, по мнению В.И. Марковина, - более четырех с половиной тысяч лет, что подтверждено методом радиоуглеродного датирования органиче- 
ских образцов [Трифонов, 2001]. Таким образом, дольмены на Кавказе были построены даже несколько раньше, чем появились египетские пирамиды.

О назначении дольменов выдвинуто множество гипотез как научного, так и фантастического характера, существуют также древние легенды и современные вымыслы. До сегодняшнего дня точное назначение дольменов до сих пор неизвестно. Постараемся рассмотреть наиболее интересные гипотезы и критически проанализировать их. Основываясь на научных материалах, анализе гипотез и легенд необходимо определить наиболее вероятное назначение дольменов. В популярной литературе относительно дольменов часто можно встретить такие «сказочные» эпитеты, как «дома карликов» и «богатырские хаты», иногда встречаются и «научнофантастические» названия, такие, например, как «стартовые площадки для НЛО» или «первобытные компьютеры». Одна из основных научных гипотез предназначения дольменов в настоящее время - сооружения для погребений. Однако она также имеет множество слабых мест.

Целью представленной работы является обоснование новой и наиболее вероятной гипотезы первоначального назначения дольменов Западного Кавказа.

Гипотезы фантастического характера необходимо отбросить сразу же, как не соответствующие основам фундаментальной науки и не имеющие научных обоснований и доказательств. А какие же аргументы свидетельствуют против основной гипотезы?

Во-первых, подавляющее большинство дольменов обнаружено без остатков их погребального содержимого. Этот факт вынудил многих исследователей предположить, что дольмены были разграблены. Однако полное отсутствие находок каких-либо человеческих останков возле большинства дольменов, которые при разграблениях должны были быть выброшены наружу, серьезно противоречит этому предположению. В связи с этим Смирновым [2010, 2015] была предложена концепция последовательной сменяемости захоронений в дольменах. Пустоту дольменов он объясняет существованием билокального погребального обряда, т. е. обряда с двумя локусами погребений, где первый во времени имеет временное использование [Смирнов, 2015]. Останки людей обнаружены только в единичных дольменах, они разрознены, зачастую детские, и, кроме того, среди них встречают кости домашних животных (особенно часто собак) [Марковин, 1985].

Во-вторых, дольмены расположены в основном недалеко от речных русел, ручьев, родников, т. е. в наиболее удобных местах для проживания людей, что противоречит практике строительства сооружений для погребений.

В-третьих, этой гипотезе не соответствует и конструкция дольменов - маленькое и очень низко расположенное входное отверстие (рис. 1).

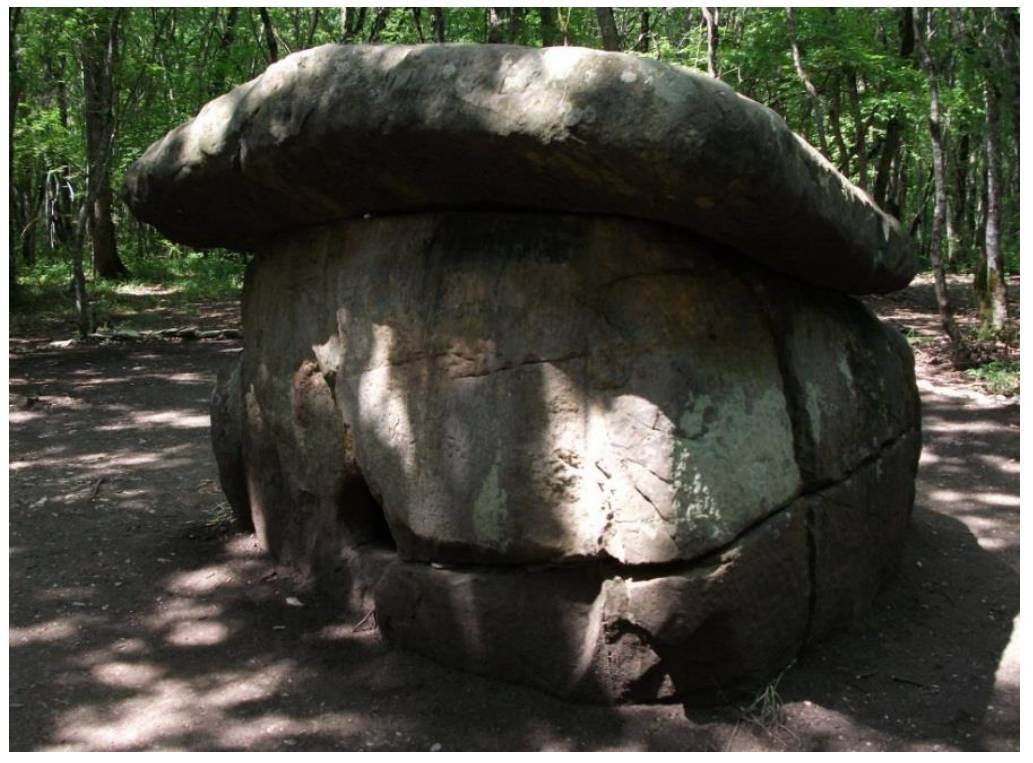

Рис. 1. Полумонолитный дольмен возле станицы Шапсугской Абинского района Краснодарского края Fig. 1. Semi-monolithic dolmen near the village Shapsugskaya of the Abinsky district of the Krasnodar region 
Все приведенные аргументы свидетельствуют о несостоятельности гипотезы о предназначении дольменов как сооружения для погребений.

Как известно, дольмены на Кавказе датированы эпохой ранней и средней бронзы, III-II тысячелетием до нашей эры и использовались до I тысячелетия до нашей эры во времена мегалитической культуры [БСЭ, 1972]. Таким образом, чтобы выяснить истинное назначение дольменов, необходимо провести всесторонний анализ имеющихся научных материалов и изучить условия и образ жизни живших в то время людей.

Выполнив указанные исследования, следует заключить, что, на наш взгляд, первоначальное основное назначение дольменов - укрытие для детей от крупных хищников, случайных одиночных охотников из других племен и некоторых стихийных явлений. Позднее часть дольменов действительно могла быть использована для погребения. В пользу выдвинутой нами гипотезы свидетельствуют многочисленные детали, которые мы и постараемся привести в данной работе.

Во-первых, как было отмечено выше, большинство дольменов (и одиночных, и групповых) находится в долинах, по берегам рек или рядом с другими источниками воды, занимая поляны или террасообразные уступы у подножия гор [Гей, 2003]. По сути, дольмены расположены столь выгодно и таким образом, что не оставляет сомнений предположение, что они находились в местах компактного проживания групп людей и использовались в повседневной жизни. А расположение одиночное или группами свидетельствует о количестве семей, проживающих в данном месте.

Во-вторых, размеры дольменов красноречиво свидетельствуют о своих «пользователях». В связи с этим отпадает надобность в поиске «карликов», живших в них. Так, например, высота дольменов редко превышает 130-140 см [Марковин, 1978], что соответствует росту детей примерно до 9-10 лет [Юрьев и др., 2007]. Еще более красноречивым является тот факт, что диаметр входного отверстия (лаза) дольменов вполне определенного размера, обычно составляет 30-40 см [Марковин, 1978, 1985], что соотносится с размерами тела детей примерно той же возрастной группы [Юрьев и др., 2007].

Интересно также то, что дольмены передней стороной чаще всего ориентированы на юг, чуть реже - на восток или юго-восток, редко на запад или юго-запад и очень редко на север, северо-восток и северо-запад [Марковин, 1978]. Строители целенаправленно ориентировали дольмены таким образом, чтобы фасад, по возможности, выходил на теплую, солнечную сторону. Этот вывод перекликается с заключением, приведенным в монографии Шарикова и Комиссара, которое гласит, что строители дольменов размещали их таким образом, чтобы они были хорошо освещены [Шариков, Комиссар, 2011]. А тот факт, что почти десятая часть этих сооружений ориентирована на запад или в северном направлении как раз противоречит именно «ритуальной черте» их строительства, так как «правила культа» являются довольно жесткими, и в этом случае дольмены были бы расположены определенным образом. В данном же случае строители руководствовались в первую очередь удобством и комфортом при их использовании.

Всѐ это свидетельствует о том, что дольмены в большинстве случаев не являлись склепами, а служили укрытием в первую очередь детского населения. Дольмены и сооружались таким образом, чтобы дети могли свободно попасть внутрь укрытия через отверстие, а крупный хищник или взрослый человек из враждебного племени - нет, ведь массивные плиты или даже крупные блоки не позволяли им разрушить дольмен (рис. 2). По данным Марковина, более 90 \% всех дольменов составлены из многотонных плит. А часть дольменов и вовсе являются полумонолитными или монолитными. В частности, монолитный дольмен полностью высекался в скале через отверстие или лаз, который еще и закрывался втулкой.

В-третьих, в тех дольменах, в которых обнаружены скелеты, их позы различны и говорят скорее не о специальных захоронениях, а являются естественными человеческими позами: поза сидящего, прижавшегося к стене человека, поза лежащего на боку человека, так называемые «скорченные захоронения».

Вполне вероятно, что эти люди умерли в указанных позах. Марковин В.И. в своей монографии [Марковин, 1985] отмечает, что позы скелетов похожи на естественные, но объясняет этот факт своеобразным «замыслом» устроителей погребений. 


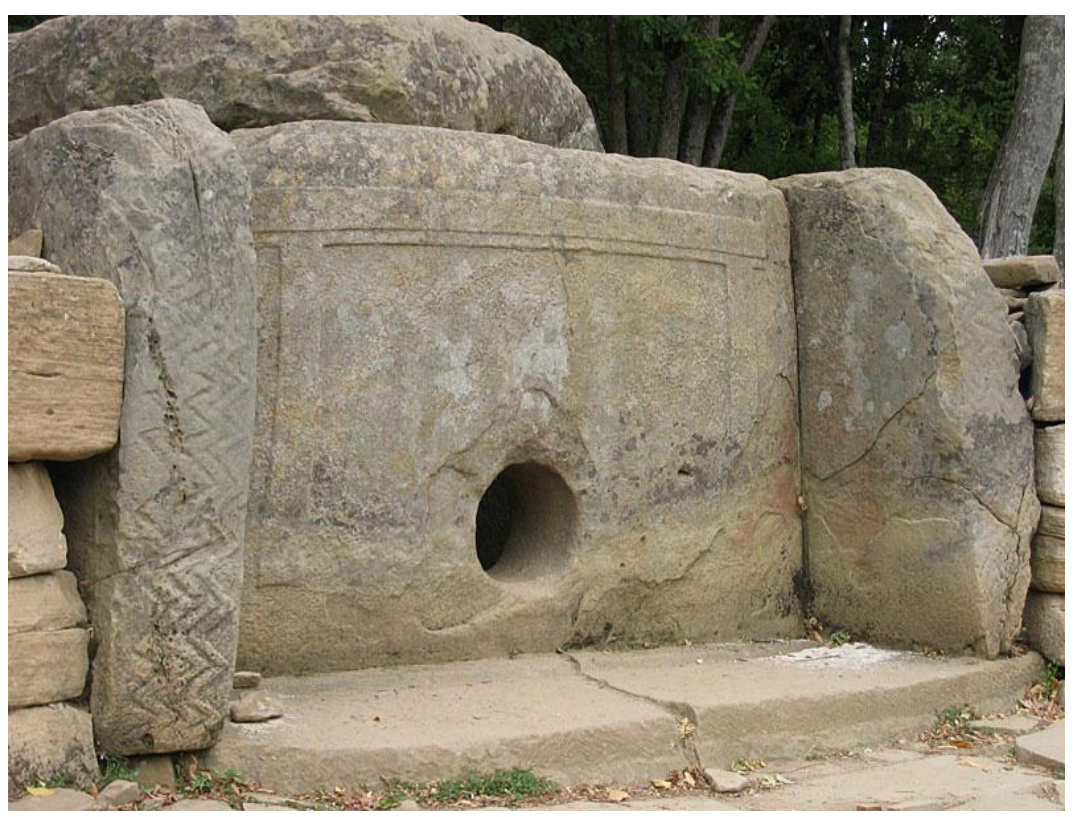

Рис. 2. Составной дольмен на берегу реки Жане в Геленджикском районе Краснодарского края Fig. 2. A composite dolmen on the banks of the Zhane river in the Gelendzhik district of the Krasnodar region

В-четвертых, конкретное предназначение дольменов можно легко понять, представив социальную и возрастную структуру, а также образ жизни проживающего в то время населения. Взрослые члены общин вынуждены были ежедневно «добывать хлеб насущный» и на весь день покидали место расположения стоянок. Маленькие дети не могли еще сопровождать взрослых и помогать им, поэтому являлись легкой добычей, в основном для хищников. Наибольшую опасность для детей представляли обитавшие в те времена многочисленные крупные хищные млекопитающие, такие как медведи, волки, шакалы, гиены, леопарды, тигры, львы [Верещагин, 1959; Алексеева, 1977; Материалы..., 1993]. Угрозу для детей представляли и случайно забредшие чужаки, а также неблагоприятные факторы окружающей среды, такие как град, снег, ураган, селевые потоки и другие. Однако эту проблему можно было легко решить, построив такие сооружения, чтобы дети могли легко проникать в них и легко покидать, а хищники или враги - нет.

В заключение хотелось бы привести любопытную легенду (сказание) адыгов, которая гласит, что дольмены являлись «домами карликов», которые были построены для них «великанами» или «нартами» [Джанджугазова, 2014]. Причем эти «карлики» ездили на «зайцах». На наш взгляд, эти сказания, хотя и приобрели «фантастический» характер с течением времени, пересказывают реальные события. В действительности «карлики»- это дети, а в роли «зайцев» могли выступать домашние собаки, к тому же охраняющие их. До сих пор в сельской местности можно иногда наблюдать картину, когда маленькие дети пытаются оседлать этих домашних питомцев. Интересно, что Марковин В.И. подчеркивает, что кости собак настолько часто встречаются при раскопках дольменов, что можно подумать, что их мясо употребляли в пищу [Марковин, 1985]. Однако далее сам отвечает на этот вопрос отрицательно, так как на поселениях среди жилья, где кости других животных встречаются во множестве, останки собак не найдены.

Таким образом, анализ приведенных нами данных свидетельствует о том, что первоначальное основное назначение большинства дольменов Западного Кавказа - это укрытие для детей, и лишь позднее часть из них могла быть превращена в места погребений. Эта гипотеза хорошо согласуется с адыгейской легендой о том, что дольмен - это «дом карликов», ведь дети и есть по сути «карлики», то есть маленькие люди, со временем, конечно, становившиеся взрослыми, то есть «великанами». По-видимому, сказания, передававшиеся из «уст в уста», сохранили основные элементы реальной истории, превратившись с течением времени в красивую легенду. 


\section{Список литературы}

1. Алексеева Л.И. 1977. Териофауна раннего антропогена Восточной Европы. Труды ГИН АН СССР. Вып. 300. М., Наука, 216.

2. Барышников Г.Ф. 1993. Крупные млекопитающие ашельской стоянки в пещере Треугольная на Северном Кавказе. В кн.: Материалы по мезозойской и кайнозойской истории наземных позвоночных. Под ред. Г.Ф. Барышникова, И.Е. Кузьминой. Труды зоологического института. Т. 249. СПб., Российская академия наук: 3-47.

3. Большая Советская Энциклопедия. 1952. Докеры - Железняков. Т. 15. М., Большая Советская Энциклопедия, 652.

4. Большая Советская Энциклопедия. 1972. Дебитор - Евкалипт. Т. 8. М., Советская Энциклопедия, 592.

5. Верещагин Н.К. 1959. Млекопитающие Кавказа. Л., Ленинградское отделение Издательства АН СССР, 704.

6. Гей А.Н. 2005. Исследование древних памятников Западного Кавказа (О работах СевероКавказской экспедиции в 2003 г.). Краткие сообщения Института археологии. Вып. 219. М., Наука: 36-49.

7. Джанджугазова Е.А. 2014. Дольмены Западного Кавказа: загадки, мифы, легенды. Современные проблемы сервиса и туризма, 3: 85-94.

8. Марковин В.И. 1973. Дольмены Западного Кавказа (некоторые итоги изучения). Советская археология, 1: 3-23.

9. Марковин В.И. 1974. Дольменная культура и вопросы раннего этногенеза абхазоадыгов. Нальчик, Эльбрус, 54.

10. Марковин В.И. 1978. Дольмены Западного Кавказа. М., Наука, 328.

11. Марковин В.И. 1985. Испун - дома карликов: Заметки о дольменах Западного Кавказа. Краснодар, Книжное издательство, 112.

12. Марковин В.И. 1994. Дольмены Западного Кавказа. В кн.: Археология. Эпоха бронзы Кавказа и Средней Азии. Ранняя и средняя бронза Кавказа. М., Наука: 226-253.

13. Марковин В.И. 1997. Дольменные памятники Прикубанья и Причерноморья. М., ОНТИ ПНЦ РАН, 403.

14. Марковин В.И. 2000. Дольмены Западного Кавказа: мистика, научные мнения и перспективы дальнейшего изучения. Российская археология, 4: 26-42.

15. Марковин В.И. 2004. Дискуссионные проблемы в изучении дольменов Западного Кавказа. В кн.: Мунчаев Р.М., Кореневский С.Н. Проблемы древней истории и культуры Северного Кавказа. М., Институт археологии РАН: 49-61.

16. Смирнов А.М. 2010. Пустой дольмен: утрата источника или норма погребальной практики. Stratum plus. Археология и культурная антропология, 2: 169-184.

17. Смирнов А.М. 2015. «Ограбленные» дольмены Кавказа и билокальный погребальный обряд. Stratum plus. Археология и культурная антропология, 2: 111-118.

18. Трифонов В.А. 2001. Что мы знаем о дольменах Западного Кавказа и чему учит история их изучения? В кн.: Дольмены. Современники древних цивилизаций. Краснодар, Краснодарское книжное издательство: 20-55.

19. Шариков Ю.Н., Комиссар О.Н. 2011. Дольмены Кавказа: геологические аспекты и технологии строительства. Краснодар, Советская Кубань, 208.

20. Юрьев В.В., Симаходский А.С., Воронович Н.Н., Хомич М.М. 2000. Рост и развитие ребенка. СПб., СПбГПМА, 197.

\section{References}

1. Alekseeva L.I. 1977. Teriofauna rannego antropogena Vostochnoy Evropy [Early anthropogene theriofauna of East Europe]. Trudy GIN AN SSSR [Academy of Sciences of tbe USSR Order of the Bed Banner of Labour Geological Institute Transactions]. Vyp. 300. M., Nauka, 216.

2. Baryshnikov G.F. 1993. Krupnye mlekopitayushchie ashel'skoy stoyanki v peshchere Treugol'naya na Severnom Kavkaze [Large mammals of the Acheulean site in the Treugolnaya Cave of the North Caucasus]. V kn.: Materialy po mezozoyskoy i kaynozoyskoy istorii nazemnykh pozvonochnykh [Materials of mesozoic and cenzoic histiry of terrestrial vertebrates]. Pod red. G.F. Baryshnikova, I.E. Kuz'minoy. Trudy zoologicheskogo instituta. T. 249. SPb., Rossiyskaya akademiya nauk: 3-47. 
3. Bol'shaya Covetskaya Entsiklopediya [Great Soviet Encyclopedia]. 1952. Dokery Zheleznyakov. T. 15. M., Bol'shaya Sovetskaya Entsiklopediya, 652.

4. Bol'shaya Covetskaya Entsiklopediya [Great Soviet Encyclopedia]. 1972. Debitor - Evkalipt. V. 8. M., Soviet Encyclopedia, 592 p.

5. Vereschagin N.K. 1959. Mlekopitayuschie Kavkaza [Mammals of the Caucasus]. L., Publ. Leningradskoe otdelenie Izdatel'stva AN SSSR, 704.

6. Gei A.N. 2005. Issledovanie drevnih pamyatnikov Zapadnogo Kavkaza (O rabotah SeveroKavkazskoi expeditsii v 2003 g.). Kratkie soobchenya instituta arheologii. Vyp. 219. [Investigation of ancient monuments of the West Caucasus (The North Caucasus expedition, season of 2003). Brief Communications from the Institute of Archeology. Vol. 219]. M., Publ. Nauka: 36-49.

7. Dzhandzhugazova E.A. 2014. Dol'meni Zapadnogo Kavkaza: zagadki, mifi, legendi [Dolmens of the Western Caucasus: riddles, myths, legends]. Sovremennie problemi servisa i turizma, 3: 85-94.

8. Markovin V.I. 1973. Dol'meni Zapadnogo Kavkaza (nekotorie itogi izucheniya) [Dolmens of the Western Caucasus (some results of the study)]. Sovetskaya archeologiya, 1: 3-23.

9. Markovin V.I. 1974. Dol'mennaya kultura i voprosi rannego etnogeneza abchazo-adigov [Dolmen culture and issues of early ethnogenesis of Abkhaz-Circassians]. Nalchik, Publ. Elbrus, 54.

10. Markovin V.I. 1978. Dol'meni Zapadnogo Kavkaza [Dolmens of the Western Caucasus]. M., Publ. Nauka, 328.

11. Markovin V.I. 1985. Ispun - doma karlikov: Zametki o dol'menah Zapadnogo Kavkaza [Ispunhouses of dwarfs: Notes on dolmens of the Western Caucasus]. Krasnodar, Publ. Knizhnoe izdatel'stvo, 112.

12. Markovin V.I. 1994. Dol'meni Zapadnogo Kavkaza [Dolmens of the Western Caucasus]. V kn.: Archeologiya. Epoha bronzi Kavkaza i Srednei Azii. Ranyaya i srednyaya bronza Kavkaza [Archeology. Bronze Age of the Caucasus and Central Asia. Early and middle bronze of the Caucasus]. M., Publ. Nauka: 226-253.

13. Markovin V.I. 1997. Dol'mennie pamyatniki Prikuban'ya i Prichernomor'ya [Dolmen monuments of the Kuban and Black Sea regions]. M., Publ. ONTI PNC RAN, 403.

14. Markovin V.I. 2000. Dol'meni Zapadnogo Kavkaza: mistika, nauchnie mneniya mnenya perspektivi dal'neishego izucheniya [Dolmens of the Western Caucasus: mysticism, scientific opinions and prospects for further study]. Rossiyskaya archeologiya, 4: 26-42.

15. Markovin V.I. 2004. Diskussionne problemi v izuchenii dol'menov Zapadnogo Kavkaza [Discussion problems in the study of dolmens of the Western Caucasus]. V kn.: Munchaev R.M., Korenevsky S.N. Problemi drevnei istorii i kulturi Severnogo Kavkaza [Problems of the ancient history and culture of the Northern Caucasus]. M., Publ. Institut arheologii RAN: 49-61.

16. Smirnov A.M. 2010. Pustoy dol'men: utrata istochnika ili norma pogrebal'noy praktiki [Emptiness of Dolmens: Lost Source or a Norm of Burial Practice]. Stratum plus. Arkheologiya i kul'turnaya antropologiya, 2: 169-184.

17. Smirnov A.M. 2015. «Ograblennye» dol'meny Kavkaza i bilokal'nyy pogrebal'nyy obryad [«Looted» Dolmens of the Caucasus and the Bilocal Funerary Rite]. Stratum plus. Arkheologiya i kul'turnaya antropologiya, 2: 111-118.

18. Trifonov V.A. 2001. Chto mi znaem o dol'menah Zapadnogo Kavkaza i chemu uchit istoriya ih izucheniya? [What do we know about the dolmens of the Western Caucasus and what does the history of their study teach?] Dol'meni. Sovremenniki drevnih tsivilisatsii. [Dolmens. Contemporaries of ancient civilizations]. Krasnodar, Publ. Krasnodarskoe knizhnoe izdatel'stvo: 20-55.

19. Sharikov Yu.N., Komissar O.N. 2011. Dol'meni Kavkaza: geologicheskie aspekti i technologii stroitel'stva [Dolmens of the Caucasus: geological aspects and construction technologies]. Krasnodar, Publ. Sovetskaya Kuban, 208.

20. Yur'ev V.V., Simahodskii A.S., Voronovich N.N., Homich M.M. , 2000. Rost i razvitie rebenka [Growth and development of the child]. Saint-Petersburg, Publ. SPbGPMA, 197.

\section{Ссылка для цитирования статьи Link for article citation}

Бондарев Н.И., Бондарева Т.А. 2020. Назначение дольменов Западного Кавказа. Via in tempore. История. Политология, 47(1): 107-112. DOI 10.18413/2687-0967-2020-47-1-107-112

Bondarev N.I., Bondareva T.A. 2020. Intention of the Western Caucasus dolmens. Via in tempore. History and political science, 47(1): 107-112 (in Russian).

DOI 10.18413/2687-0967-2020-47-1-107-112 